\title{
Factor Analysis of Competency of Computer Teacher at Vocational Certificate Level
}

\author{
Punnee Leekitchwatana, Paitoon Pimdee, Sangutai Moto \\ Faculty of Industrial Education, King Mongkut's Institute of Technology Ladkrabang, \\ Bangkok, Thailand \\ Email: klpunnee@kmitl.ac.th
}

Received February $27^{\text {th }}, 2013$; revised March $28^{\text {th }}, 2013$; accepted April $12^{\text {th }}, 2013$

\begin{abstract}
Copyright (C) 2013 Punnee Leekitchwatana et al. This is an open access article distributed under the Creative Commons Attribution License, which permits unrestricted use, distribution, and reproduction in any medium, provided the original work is properly cited.
\end{abstract}

\begin{abstract}
The research objectives were to analysis the factor and construct the questionnaire on competency of computer teacher at vocational certificate level of educational institute under Office of Vocational Education Commission (OVEC). The descriptive research and structural relationship model were used for the study. Sample groups comprised of 1) 90 experts and 2) 200 educational institutes under OVEC. Research instruments were questionnaires on competency of computer teacher at vocational certificate level for: 1) experts and 2) educational institutes. Data analysis were conducted with: 1) Exploratory factor analysis by using SPSS for Windows for data from experts, 2) The second order confirmatory factor analysis with LISREL 8.72 program and Cronbach's $\alpha$ formula for data from educational institutes. Research results revealed that competency of computer teacher at vocational certificate level composed of 12 components from 62 variables covered 3 domains of knowledge, skill, and affection. Those 12 components were general knowledge about education, knowledge about curriculum, knowledge about teaching, knowledge about e-Learning and e-Media, knowledge about IT support, knowledge about computer use, teaching skill, skill about e-Learning and e-Media, skill about IT support, skill for using computer, supportive affection to be a teacher and affection in IT. The questionnaire on competency of computer teacher had good quality with good construct validity and high reliability in 2 dimensions of intent and actual competencies.
\end{abstract}

Keywords: Factor Analysis; Competency of Computer Teacher; Vocational Certificate Level

\section{Introduction}

The rapid growth of global economic and technology affected to Thailand, therefore Thai government had policy to mobilize the country and Thai society to new economic system based on knowledge development to increase competency competition. Readiness preparation of man power to face with new economic with attributes of physical infrastructure and effective technology are very important and essential issues (OVEC, 2005).

Computerized technology is a very important tool for work implementation in different occupations, therefore the vocational certificate curriculum of every program has computer subject for vocation as fundamental subject for every student to take course. If the student at vocational certificate level fully obtains computer subject for vocation according to curriculum, it would be beneficial for student to apply to use in his career effectively and it provides high advantage for various work units and work places.

Educational management with good quality in accordance with curriculum, teacher is the most important factor to aid for learning, therefore the teacher should fully manage learning and teaching for student according to aim of curriculum. Consequently, he needs to have proper competency to take responsibility and readiness of competency of knowledge, skill, and affection. Management of learning and teaching computer subject for vocation, it also needs the teacher who owns covering 3 domains as mentioned. However, at present, it is not obvious evident to point clearly whether components are important for better competency of computer teacher for vocation at vocational certificate level and how much competency he has, and what part that it needs to be developed. Therefore, researchers are interested in studying the component of competency of computer teacher at vocational certificate level and construct the questionnaire of competency of computer teacher at vocational certificate level for educational institute to use for need assessment and for development of competency of computer teacher further.

\section{Objectives}

1) To analysis the factor of competency of computer teacher for vocation at vocational certificate level.

2) To construct the questionnaire of competency of computer teacher for vocation at vocational certificate level.

\section{Hypotheses}

1) The studied variables were able to be in components of competency of computer teacher at vocational certificate level. 
2) The questionnaire of competency of computer teacher at vocational certificate level had good construct validity and high reliability.

\section{Conceptual Framework}

Prototype components of competency of computer teacher at vocational certificate level composed of 3 domains that were knowledge, skill and affection. Each domain composed of 2 components therefore there were 6 components that were applied from 6 prototype components of competency of IT teacher of Leekitchwatana (2010) in Table 1.

\section{Research Scope}

\section{Population Scope}

1) Population for the factor analysis were experts in teaching computer subject/IT subject.

2) Population for the examination the quality of questionnaire were 414 educational institutes where open vocational certificate level under Office of Vocational Education Commission (OVEC) in academic year of 2011 (OVEC, 2011).

\section{Content Scope}

Content scope of competency of computer teacher for vocation covered 3 domains. Each domain had 2 components and total were 6 components as mentioned in Table 1.

\section{Research Implementation}

\section{Research Steps}

Research methodology was descriptive research composed of 2 parts as the followings.

1) Factor analysis of competency of computer teacher for vocation by constructing prototype components from documents and related literatures to be the questionnaire for data collection from experts sample group, then data was analyzed with exploratory factor analysis (EFA).

2) Examination the quality of questionnaire on competency of computer teacher for vocation for educational institute by using component that was results of exploratory factor analysis mentioned in item 1) to construct the questionnaire and use it to collect data from the education institute sample group, then data analysis was done with statistics of second order confirmatory factor analysis $\left(2^{\text {nd }}\right.$ order CFA) and calculated the reliability with $\alpha$ formula of Cronbach.

\section{Sample Groups}

1) Sample group used for the factor analysis of competency

Table 1.

Prototype components of competency of computer teacher.

\begin{tabular}{ll}
\hline Domain & \multicolumn{1}{c}{ Component } \\
\hline 1. Knowledge & $\begin{array}{l}\text { 1. Knowledge in teacher professional } \\
\text { 2. Knowledge in computer subject for vocation }\end{array}$ \\
2. Skill & $\begin{array}{l}\text { 3. Skill in teacher professional } \\
\text { 4. Skill in computer subject for vocation }\end{array}$ \\
3. Affection & 5. Supportive affection to be a teacher \\
\end{tabular}

was 100 experts who teach computer subject/IT subject. They were selected by using network pattern.

2) Sample group used for the examination the quality of questionnaire was 200 educational institutes. The sample size was determined by using table of Krejcie and Morgan (1970) and the samples were selected by using multi-stage random sampling from population of 414 educational institutes under OVEC nationwide in academic year of 2011.

\section{Research Instruments}

1) Expert questionnaire was opinion toward the list of variables about competency of computer teacher for vocation at vocational certificate level covering 3 domains of knowledge, skill, and affection that was improved from questionnaire of Leekitchwatana (2010). It was classified as 6 prototype components from 62 variables. The attribute question was rating scale with 5 levels. The quality was content validity between $0.66-1.00$ and reliability in terms of domain between 0.91 0.95 and reliability in terms of component were $0.88-0.94$.

2) Educational institute questionnaire was opinion about competency of computer teacher for vocation at vocational certificate level in 2 dimensions of intent and actual competencies covering of 3 domains of knowledge, skill, and affection. It was classified as 12 components from 62 variables resulted from EFA in item 1). The question attribute was rating scale with 5 levels. The validity was at good level in both dimensions from the $2^{\text {nd }}$ order CFA with reliability in dimension of intent competency in terms of each domain between $0.96-0.97$ and in terms of component were $0.85-0.98$ and reliability of actual competency in terms of 3 domains were 0.95 equally and as each component between $0.78-0.95$.

\section{Data Collection}

1) The expert data were collected from expert sample group by bringing questionnaire to them and receiving back directly from 90 experts. It was 90 percents back from 100 experts setting.

2) The education institute data were collected from education institute sample group by mailing questionnaire to 200 educational institutes and received back by mailing from 200 educational institutes. It was 100 percents back from 200 sample setting.

\section{Data Analysis}

1) Factor analysis of competency from expert data with statistics EFA by extracting component with principal component analysis and orthogonal rotation with varimax method by using SPSS for Windows program, and using criteria consideration for component and variable to be used as the followings.

a) Component with eigenvalue more than 1.00.

b) Variable with factor loading initiation of 0.40 .

2) Examination the quality of questionnaire from educational institute data as the followings.

a) Analysis the construct validity with $2^{\text {nd }}$ order CFA by using LISREL 8.72 program and using criteria consideration for model confirmation with empirical data that applied from some part of Wiruchchai (1995) and Ungsuchote et al. (2008) as the Chi-square has no statistical significance at level of 0.05 ( $p>$ $0.05)$, RMSEA $<0.05$, GFI $>0.90$, AGFI $>0.90$, RMR $<0.05$ 
and $\mathrm{SRMR}<0.05$

b) Calculate the reliability with $\alpha$ formula of Cronbach and using criterion at good level with initiation of 0.80 .

\section{Research Results}

\section{Results of Factor Analysis of Competency of Computer Teacher for Vocation}

1) $\mathrm{KMO}$ or MSA equaled to 0.693 , it indicated that this set of variables was proper for factor analysis at moderate level according to criteria of Hair et al. (1998). The result of Bartlett's test of sphericity, it was found that variables were related with statistically significant at 0.000 . These illustrated that various variables were related and were able to use for factor analysis.

2) Result of extraction with principal component analysis, communality was found in 62 variables that were used for factor analysis of competency between $0.430-0.902$ as moderate to more size. The tendency was able to classify into component.

3) Result of orthogonal rotation with varimax method showed in Table 2.

From Table 2, it was found that 62 variables were used to analyze, these were grouped to be 14 components with eigenvalue more than 1.00 . It indicated that each component was able to explain the variation of 62 variables more than 1.00 . The whole 14 components were able to explain variation of 62 variables with 81.719 percents.

In order to group various variables to be in only one component with the highest factor loading, it was found that the 62 variables were able to be grouped into 13 components, therefore each component composed of 2 - 11 variables. Each variable was grouped into component would have factor loading between 0.430 to 0.902 .

Result of grouping as mentioned above, it was found that some component composed of 11 variables and they were in the different domains while some component composed of only 2 variables. Therefore, it was minor adjusted structure of component in order to group by letting the each component composed of the variable from the same domain and the numbers of variables were not much different, then there were 12 components from 62 variables. The adjusted components were named to give meaning with congruence to cover all variables in each component.

4) Result of adjust variable grouped and named the component showed in Table 3.

\section{Results of Examination the Quality of Questionnaire Competency of Computer Teacher for Vocation}

\section{Results of Construct Validation with Confirmatory Factor} Analysis (CFA)

Results of the $2^{\text {nd }}$ order CFA of intent and actual competencies as showed in Figures $\mathbf{1}$ and $\mathbf{2}$ and Tables $\mathbf{4}$ and $\mathbf{5 .}$

From Figure 1 and Table 4, it was found that the model of intent competency of computer teacher for vocation at vocational certificate level was congruent to empirical data of educational institutes under OVEC at good level because every statistic value to measure the confirmation passed every criterion. It illustrated that model with good validity and it illustrated the structure of content in questionnaire had good validity and it confirmed that teacher competency composed of 3 factors from 12 sub-factors. The important sequences of factors were knowledge, skill, and affection respectively. Moreover, the important sequences of sub-factors in each factor, the factor of knowledge were knowledge about teaching, knowledge

Table 2.

Orthogonal rotation with varimax method.

\begin{tabular}{|c|c|c|c|c|c|c|}
\hline \multirow{2}{*}{ Component } & \multicolumn{3}{|c|}{ Extraction Sums of Squared Loadings } & \multicolumn{3}{|c|}{ Rotation Sums of Squared Loadings } \\
\hline & Total (Eigenvalue) & $\%$ of Variance & Cumulative \% & Total (Eigenvalue) & $\%$ of Variance & Cumulative \% \\
\hline 1 & 22.323 & 36.005 & 36.005 & 7.852 & 12.664 & 12.664 \\
\hline 2 & 5.768 & 9.303 & 45.308 & 6.753 & 10.891 & 23.555 \\
\hline 3 & 4.039 & 6.515 & 51.824 & 4.692 & 7.567 & 31.122 \\
\hline 4 & 2.742 & 4.423 & 56.246 & 4.295 & 6.927 & 38.050 \\
\hline 5 & 2.392 & 3.859 & 60.105 & 3.983 & 6.425 & 44.474 \\
\hline 6 & 2.139 & 3.450 & 63.555 & 3.736 & 6.027 & 50.501 \\
\hline 7 & 2.109 & 3.401 & 66.956 & 3.555 & 5.734 & 56.235 \\
\hline 8 & 1.912 & 3.084 & 70.040 & 3.551 & 5.727 & 61.962 \\
\hline 9 & 1.555 & 2.508 & 72.548 & 3.046 & 4.913 & 66.874 \\
\hline 10 & 1.325 & 2.137 & 74.685 & 2.443 & 3.940 & 70.814 \\
\hline 11 & 1.191 & 1.921 & 76.606 & 2.208 & 3.562 & 74.376 \\
\hline 12 & 1.096 & 1.768 & 78.374 & 1.913 & 3.086 & 77.462 \\
\hline 13 & 1.067 & 1.721 & 80.095 & 1.419 & 2.289 & 79.751 \\
\hline 14 & 1.007 & 1.624 & 81.719 & 1.220 & 1.967 & 81.719 \\
\hline
\end{tabular}




\section{P. LEEKITCHWATANA ET AL.}

Table 3.

Structure and name of components of competency of computer teacher for vocation at vocational certificate level after adjust.

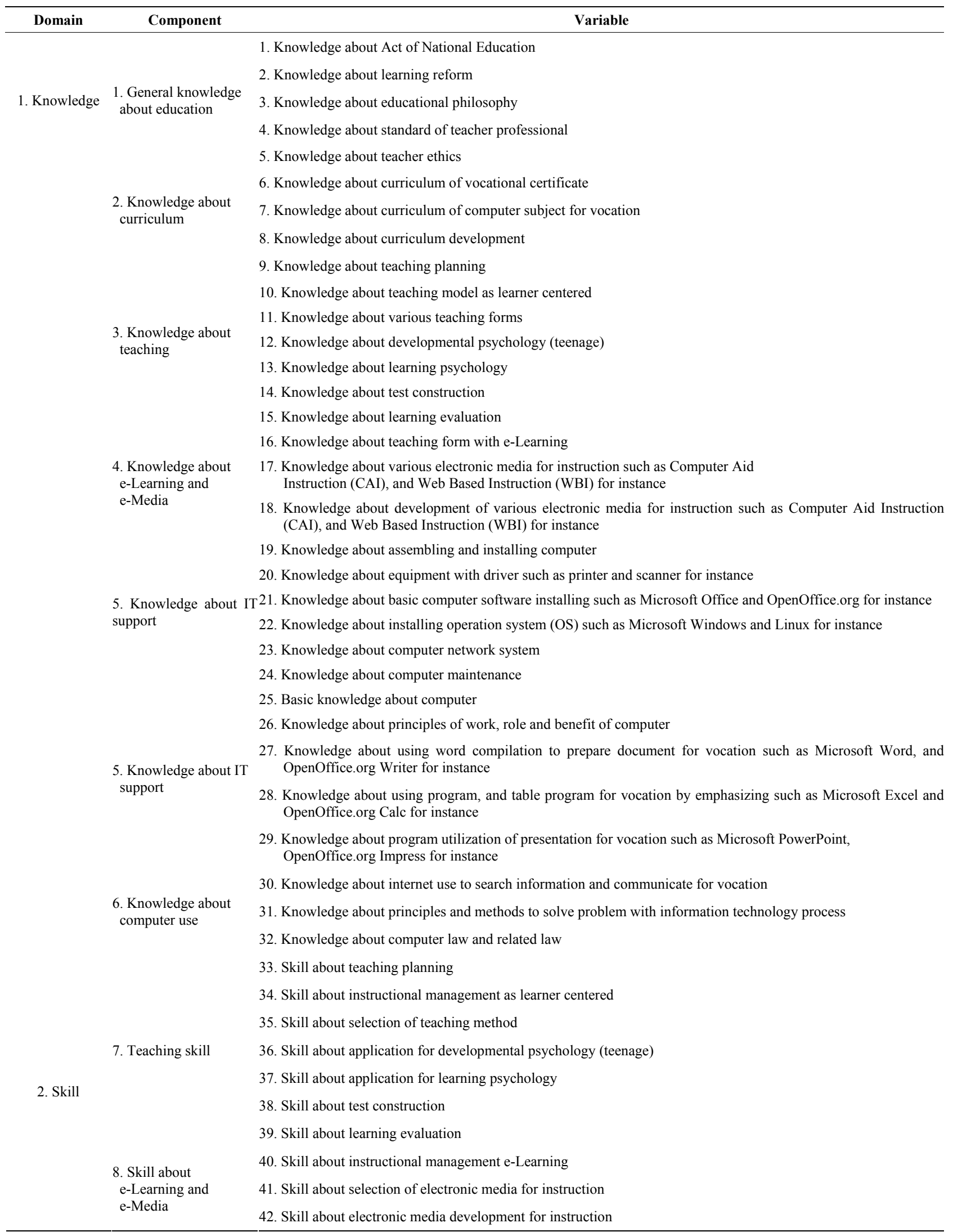




\section{P. LEEKITCHWATANA ET AL.}

Continued

\begin{tabular}{|c|c|c|}
\hline Domain & Component & Variable \\
\hline & & 43. Skill about assembling and installing computer \\
\hline & & 44. Skill about installing equipment with driver \\
\hline & & 46. Skill about installing operational system (OS) \\
\hline & & 47. Skill about computer maintenance \\
\hline & 10 Skill for $u \sin g$ & 49. Skill for using program and table program for vocation \\
\hline & computer & 50. Skill for using presentation program for vocation. \\
\hline & & 51. Skill for using internet to search information and communicate for vocation \\
\hline & & 52. Skill for problem solving with IT process \\
\hline & & 53. Ethics of teacher professional \\
\hline & 11. Supportive & 54. To be a person of learning \\
\hline & Affection to be a & 55. Achievement motive \\
\hline & Teacher & 56. Future oriented and self of control \\
\hline \multirow{6}{*}{ 3. Affection } & & 57. Attitude toward electronic media use for instruction \\
\hline & & 58. Attitude toward computer \\
\hline & & 59. Attitude toward internet \\
\hline & 12. Affection in IT & 60. Attitude toward IT media \\
\hline & & 61. Ethics in IT use \\
\hline & & 62. Readiness for change \\
\hline
\end{tabular}

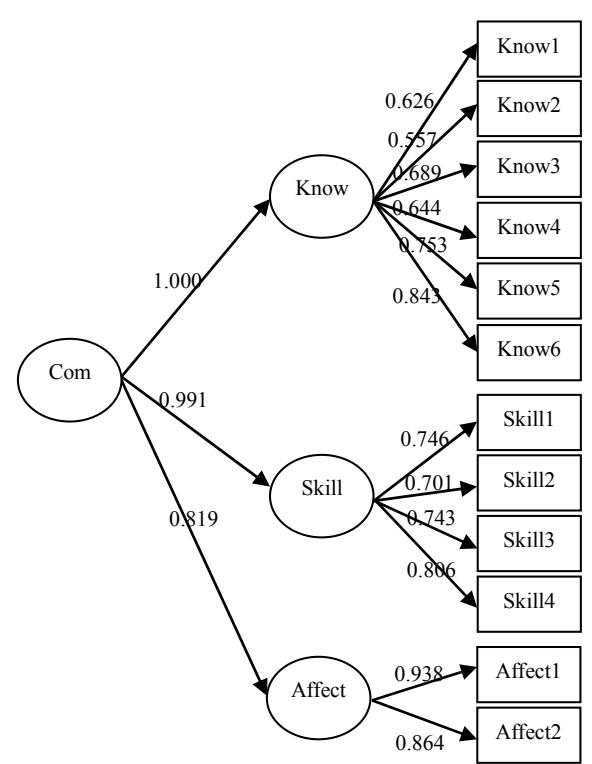

Chi-Square $=38.990, \mathrm{df}=28, \mathrm{P}$-value $=0.081, \mathrm{RMSEA}=0.044$

Figure 1.

Intent Competency Model.

about e-Learning and e-Media, knowledge about computer use, knowledge about IT Support, knowledge about curriculum and general knowledge about education respectively. The factor of skill were teaching skill, skill about IT Support, skill about e-Learning and e-Media, and skill for using computer respectively. The factor of affection were supportive affection to be a teacher and affection in IT respectively. From Figure 2 and Table 5, it was found that the model of actual competency of computer teacher for vocation at vocational certificate level was

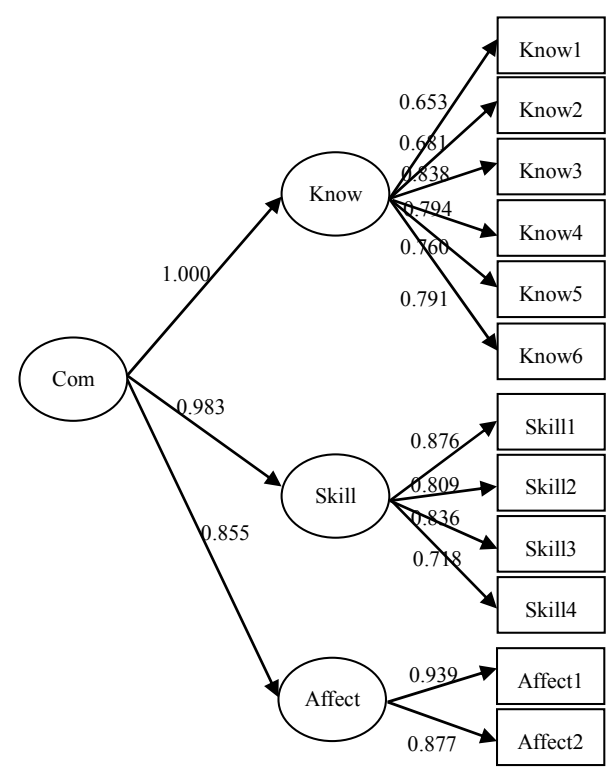

Chi-Square $=30.542, \mathrm{df}=29, \mathrm{P}$-value $=0.387, \mathrm{RMSEA}=0.016$

Figure 2.

Actual Competency Model.

Congruent to empirical data of educational institutes under OVEC at good level because every statistic value to measure the confirmation passed every criterion. It illustrated that model with good validity and it illustrated the structure of content in questionnaire had good validity and it confirmed that teacher competency composed of 3 factors from 12 sub-factors. The important sequences of factors were knowledge, skill, and affection respectively. Moreover, the important sequences of sub-factors in each factor, the factor of knowledge were knowl- 
Table 4.

Results of the $2^{\text {nd }}$ order CFA of intent competency.

\begin{tabular}{|c|c|c|c|c|}
\hline Factor/Sub-factor & Factor Loading & Standard Factor Loading & Prediction Coefficient $\left(\mathbf{R}^{2}\right)$ & Rank \\
\hline Knowledge & $1.000^{* * *}$ & $1.000^{* *}$ & $1.000^{* *}$ & 1 \\
\hline Skill & $0.983^{* *}$ & $0.983^{* *}$ & $0.966^{* *}$ & 2 \\
\hline Affection & $0.855^{* *}$ & $0.855^{* *}$ & $0.731^{* *}$ & 3 \\
\hline Know 1 (General knowledge about education) & $0.374^{* *}$ & $0.653^{* *}$ & $0.426^{* *}$ & 6 \\
\hline Know 2 (Knowledge about curriculum) & $0.359^{* *}$ & $0.681^{* *}$ & $0.464^{* *}$ & 5 \\
\hline Know 3 (Knowledge about teaching) & $0.459^{* *}$ & $0.838^{* *}$ & $0.703^{* *}$ & 1 \\
\hline Know 4(Knowledge about e-Learning and e-Media) & $0.520^{* *}$ & $0.794^{* *}$ & $0.630^{* *}$ & 2 \\
\hline Know 5 (Knowledge about IT Support) & $0.428^{* *}$ & $0.760^{* *}$ & $0.578^{* *}$ & 4 \\
\hline Know 6 (Knowledge about computer use) & $0.348^{* *}$ & $0.791^{* *}$ & $0.625^{* *}$ & 3 \\
\hline Skill 1 (Teaching skill) & $0.537^{* *}$ & $0.876^{* *}$ & $0.768^{* *}$ & 1 \\
\hline Skill 2 (Skill about e-Learning and e-Media) & $0.544^{* *}$ & $0.809^{* *}$ & $0.654^{* *}$ & 3 \\
\hline Skill 3 (Skill about IT Support) & $0.557^{* *}$ & $0.836^{* *}$ & $0.698^{* *}$ & 2 \\
\hline Skill 4 (Skill for using computer) & $0.346^{* *}$ & $0.718^{* *}$ & $0.516^{* *}$ & 4 \\
\hline Affect 1 (Supportive Affection to be a teacher) & $0.463^{* *}$ & $0.939^{* *}$ & $0.882^{* *}$ & 1 \\
\hline Affect 2 (Affection in IT) & $0.429^{* *}$ & $0.877^{* *}$ & $0.770^{* *}$ & 2 \\
\hline
\end{tabular}

Note: ${ }^{* *} p<0.01$

Table 5.

Results of the $2^{\text {nd }}$ order CFA of actual competency.

\begin{tabular}{|c|c|c|c|c|}
\hline Factor/Sub-factor & Factor Loading & Standard Factor Loading & Prediction Coefficient $\left(\mathbf{R}^{2}\right)$ & Rank \\
\hline Knowledge & $1.000^{* *}$ & $1.000^{* *}$ & $1.000^{* *}$ & 1 \\
\hline Skill & $0.991^{* *}$ & $0.991^{* *}$ & $0.983^{* *}$ & 2 \\
\hline Affection & $0.819^{* *}$ & $0.819^{* * *}$ & $0.671^{* *}$ & 3 \\
\hline Know 1 (General knowledge about education) & $0.375^{* *}$ & $0.626^{* *}$ & $0.392^{* *}$ & 5 \\
\hline Know 2 (Knowledge about curriculum) & $0.312^{* *}$ & $0.557^{* *}$ & $0.310^{* *}$ & 6 \\
\hline Know 3(Knowledge about teaching) & $0.355^{* *}$ & $0.689^{* *}$ & $0.475^{* *}$ & 3 \\
\hline Know 4(Knowledge about e-Learning and e-Media) & $0.452^{* *}$ & $0.644^{* *}$ & $0.414^{* *}$ & 4 \\
\hline Know 5 (nowledge about IT Support) & $0.487^{* *}$ & $0.753^{* *}$ & $0.568^{* *}$ & 2 \\
\hline Know 6 (Knowledge about computer use) & $0.423^{* *}$ & $0.843^{* *}$ & $0.710^{* *}$ & 1 \\
\hline Skill 1 (Teaching skill) & $0.426^{* *}$ & $0.746^{* *}$ & $0.557^{* *}$ & 2 \\
\hline Skill 2 (Skill about e-Learning and e-Media) & $0.543^{* *}$ & $0.701^{* *}$ & $0.492^{* *}$ & 4 \\
\hline Skill 3 (Skill about IT Support) & $0.579^{* *}$ & $0.743^{* *}$ & $0.552^{* *}$ & 3 \\
\hline Skill 4 (Skill for computer using) & $0.502^{* *}$ & $0.806^{* *}$ & $0.650^{* *}$ & 1 \\
\hline Affect 1 (Supportive Affection to be a teacher) & $0.510^{* *}$ & $0.938^{* *}$ & $0.879^{* *}$ & 1 \\
\hline Affect 2 (Affection in IT) & $0.470^{* *}$ & $0.864^{* *}$ & $0.746^{* *}$ & 2 \\
\hline
\end{tabular}

Note: ${ }^{* *} p<0.01$.

edge about computer use, knowledge about IT Support, knowledge about teaching, knowledge about e-Learning and e-Media, general knowledge about education, and knowledge about curriculum respectively. The factors of skill were skill for using computer, teaching skill, skill about IT Support, and skill about e-Learning and e-Media respectively. The factors of affection were supportive affection to be a teacher and affection in IT respectively. 


\section{Results of Calculation of Reliability with $\alpha$ Formula of Cronbach}

The intent competency of knowledge, skill, and affection were $0.96,0.97$ and 0.96 and actual competency were 0.95 , 0.95 and 0.95 respectively as shown in Table 6.

\section{Conclusion}

Results of factor analysis of competency of computer teacher at vocational certificate level from expert data with EFA, it was found that the 62 studied variables from 6 prototype components covering in 3 domains, that were able to group as component with eigenvalue more than 1.000 with 14 components and the whole components were able to explain the whole variables with 81.719 percents and factor loading of each variable between 0.430 to 0.902 . Afterward, 62 variables were minor adjusted the new structure component to be 12 components in the same 3 domains that were knowledge, skill and affection. Those 12 components were general knowledge about education, knowledge about curriculum, knowledge about teaching, knowledge about e-Learning and e-Media, knowledge about IT support, knowledge about computer use, teaching skill, skill about e-Learning and e-Media, skill about IT support, skill for using computer, supportive affection to be a teacher and affection in IT.

Results of examination the quality of questionnaire on competency of computer teacher for vocation at vocational certificate level from educational institute data.

1) It was found that the 12 competency components covering 3 competency domains including knowledge, skill and affection obtained from EFA in term 7.1, these had good construct validity because the model was congruent to empirical data at good level in both dimensions of intent and actual competencies with statistical value passed as the followings.

a) Model of intent competency had Chi-square value with no statistical significance $(p=0.387)$, RMSEA $=0.016$, GFI $=$ $0.975, \mathrm{AGFI}=0.933, \mathrm{RMR}=0.006$, and $\mathrm{SRMR}=0.021$. The important sequence of factors from most to less were knowledge, skill and affection respectively.

b) Model of actual competency had Chi-square value with no statistical significance $(p=0.081)$, RMSEA $=0.044$, GFI $=$ 0.968, AGFI $=0.912$, RMR $=0.011$, and SRMR $=0.031$. The important sequence of factors from most to less were knowledge, skill and affection respectively.

2) Moreover, it was found that the questionnaire had high reliability in both dimensions as the followings.

a) Reliability of intent competency in terms of factors with initiation $0.96-0.97$ and in terms of sub-factor with initiation $0.85-0.98$.

b) Reliability of actual competency in terms of factors with 0.95 in 3 domains and in terms of sub-factor with initiation 0.78 -0.95 .

\section{Discussion}

Results of factor analysis of competency of computer teacher at vocational certificate level, it was found that the 62 studied variables were able to be grouped into 14 components and each component had eigenvalue more than 1 . Moreover, the whole components were able to explain the variation of whole variable with 81.719 and factor loading of each variable had value with initiation 0.430 to 0.902 . This indicated that the variables are able to use for studying competency of computer teacher at vocational certificate level since these variables had document and research support. The documents and related literatures were wide reviewed therefore the important variables was obtained with congruence and covering large structure of 3 competency domains included document and research.

The whole 62 variables are able to group into 14 components, then there is minor structural component adjusted for more

Table 6.

Results of calculation of reliability of questionnaire classified by dimension in terms of factors and sub-factors.

\begin{tabular}{|c|c|c|}
\hline \multirow{2}{*}{ Factor/Sub-factor } & \multicolumn{2}{|c|}{ Reliability ( $\alpha$ ) } \\
\hline & Intent Competency & Actual Competency \\
\hline Knowledge & 0.96 & 0.95 \\
\hline Skill & 0.97 & 0.95 \\
\hline Affection & 0.96 & 0.95 \\
\hline Know 1 (General Knowledge about education) & 0.91 & 0.87 \\
\hline Know 2 (Knowledge about curriculum) & 0.85 & 0.78 \\
\hline Know 3(Knowledge about teaching) & 0.92 & 0.88 \\
\hline Know 4(Knowledge about e-Learning and e-Media) & 0.94 & 0.90 \\
\hline Know 5 (Knowledge about IT Support) & 0.94 & 0.91 \\
\hline Know 6 (Knowledge about computer use) & 0.92 & 0.89 \\
\hline Skill 1 (Teaching skill) & 0.96 & 0.92 \\
\hline Skill 2 (Skill about e-Learning and e-Media) & 0.91 & 0.92 \\
\hline Skill 3 (Skill about IT Support) & 0.98 & 0.95 \\
\hline Skill 4 (Skill for computer using) & 0.94 & 0.94 \\
\hline Affect 1 (Supportive Affection to be a teacher) & 0.94 & 0.90 \\
\hline Affect 2 (Affection in IT) & 0.96 & 0.92 \\
\hline Total & 0.98 & 0.98 \\
\hline
\end{tabular}


proper to be 12 components from the whole 62 variables covering 3 domains. Afterward these components and variables were used for constructing the questionnaire on teacher competency for educational institute and these were examined for construct validity with the $2^{\text {nd }}$ order CFA to confirm 2 issues as the followings.

1) To confirm 12 adjusted components, these were arranged into 12 sub-factors in 3 factors.

2) To confirm 3 factors, these composed to be the whole competency.

Results of examination the quality of questionnaire on competency of computer teacher at vocational certificate level for educational institute; it was found that questionnaire had good construct validity and high reliability. The $2^{\text {nd }}$ order CFA of competency composed of 12 sub-factors and 12 sub-factors were grouped into 3 factors included knowledge, skill and affection. These were factor of competency since the model was congruent to empirical data of educational institutes at good level both intent and actual competencies. Owing to the variables and factor were introduced to construct questionnaire had documents and related literature support and it was analyze with EFA, therefore when these were used to analyze with $2^{\text {nd }}$ order CFA, then it was found that construct validity was at good level.

Considering the importance of 3 factors, it is obviously seen that competency in domains of knowledge and skill are very important as the first and the second orders with factor loading almost similar. This is congruent to the importance of knowledge and skill for IT use in accordance with objective of training in model of professional teacher skill development in aspect of IT use of Downes et al. (2002).

The factor in this research is congruent to the research results of Leekitchwatana (2010) who studied on factor of competency of IT teacher at lower secondary school level and found 3 domains of knowledge, skill, and affection. The sub-factor in this research were found 12 sub-factors but she found 10 sub-factors with differences in factor of knowledge and skill of subject teaching but at vocational certificate level would have more sub-factors than lower secondary school level.

Furthermore, it is also go along with research results of Julachoo (2005) who studied competency tendency of IT teacher by using Delphi technique and found that the competency tendency of IT teacher at third level in 3 domains included knowledge, practice skill and attitude. In addition, it is congruent to study of Boonserm (2003) who studied factor of competency of art teacher at primary school level by the $2^{\text {nd }}$ order CFA and found 2 principal factors and 7 sub-factors. The congruent factors are academic, teaching skill, moral and ethic aspect, art knowledge aspect, and art skill aspect. The two last factors are knowledge and skill that are the same as this research results.

\section{Recommendations}

\section{Recommendations from the Research Results}

Factor of competency of computer teacher for vocation from this research results had the document and related literature support and was examined the validity by factor analysis 2 times that were EFA and the $2^{\text {nd }}$ order CFA. It was found that there was content validity therefore, it is able to study competency of computer teacher for vocation both intent and actual competencies.

Questionnaire on competency of computer teacher for voca- tion construct had good quality since it had good construct validity and high reliability, therefore, it is able to study competency of computer teacher for vocation both intent and actual competencies.

\section{Recommendations for Further Research}

Factor of competency of computer teacher for vocation from this research results was emphasized to be proper for teacher who is teaching if one wants to use the component regarding to extensive role of teacher or more complex role than this, it might be added competency of teacher in other domains such as researcher and head of work unit of computer/ IT for instance, therefore in order to congruent and cover with role and function of information technology teacher who has higher position and/or more responsibility, the adjusted component might use to examine the new construct validity by using EFA and/or CFA.

The variables and factors of competency of computer teacher in this research is proper for study competency of computer teacher for vocation, therefore if one wants to study competency of computer teacher in other subjects or other levels, it needs to adjust the variables and factors to be proper with content or context of that educational level, particularly variables and factors in domains of computer knowledge and skill because different subjects or different education levels of learner and different roles and functions of teacher, therefore the adjusted variables and factors can be used by examining the new construct validity and analyzing with EFA and/or CFA.

\section{Acknowledgements}

The researchers would like to express gratitude to the Higher Education Research Promotion and National Research Universities, Office of the Higher Education Commission, Thailand for supporting this study. In addition, We are deeply indebted to the Faculty of Industrial Education and King Mongkut's Institute of Technology Ladkrabang (KMITL) for giving us the opportunity to complete this study. Finally, we would like to give our special thanks to all the experts and educational institutes which were a part in this study and enabled us to complete this work.

\section{REFERENCES}

Boonserm, P. (2003). Analysis of component and study of background related to competency of art teacher at primary school level. Master Thesis, Chulalongkorn: Chulalongkorn University.

Downes, T., Khun, T., Scott, D., Leonard, R., \& Warhurst, J. (2002). Preservice Teacher Training and Teacher Professional Development in the Use of ICTs in the Teaching of Mathematics and Science in Participating SEAMEO Countries. Report Submitted to SEAMEO HOM, Bangkok, 2002.

Hair Jr., J. E., Anderson, R. E., Tatham, R. L., \& Black, W. C. (1998). Multivariate data analysis. 5th Edition, New Jersey: Prentice-Hall, Inc.

Julachoo, S. (2005). Competency tendency of information technology teacher in content group of occupation and technology in school under the office of educational area of Nakorn Nayok. Master Thesis, Kasetsart: Kasetsart University.

Krejcie, R. V., \& Morgan, D. W. (1970). Determining sample size for research activities. Journal of Educational and Psychological Measurement, 30, 607-610.

Leekitchwatana, P. (2010). Development of competency of information technology teacher at lower secondary school. Khon Kaen Research 


\section{P. LEEKITCHWATANA ET AL.}

Journal, 15, 1101-1114.

Office of Vocational Education Commission (OVEC) (2011). Education institute under office of vocational education commission.

http://www.vec.go.th/Default.aspx?tabid=113

Office of Vocational Education Commission (OVEC) (2005). Principle theory and policy of vocational education reform. http://www.vec.go.th/

Ungsuchote, S. et al. (2008). Statistical Analysis for Research in Social Science and Behavioral Science: Technique of LISREL Program. Bangkok: Mission Media.

Wiruchchai, N. (1995). Linear structural equation relationship model (LISREL). 2nd Edition, Bangkok: Chulalongkorn Press. 